\title{
The Human Side of ERP Implementations: Can Change Management Really Make a Difference?
}

\author{
Susan Foster ${ }^{1}$, Paul Hawking ${ }^{2}$ and Cindy $\mathrm{Zhu}^{3}$ \\ 'Faculty of Information Technology, Caulfield School of IT, Monash University, Melbourne \\ Australia sue.foster@infotech.monash.edu.au \\ ${ }^{2}$ School of Information Systems, Victoria University, Melbourne, Australia \\ ${ }^{3}$ Beijing Jiaotong University, Beijing, P.R. China
}

\begin{abstract}
In the lead up to large-scale change bought about by enterprise system implementations, there are multiple complex influences at play that impact perceptions that the organisation might not be ready for the change effort. These influences manifest in uncertainty, ambiguity in roles and responsibilities and in many cases, information overload. Organisational change management $(O C M)$ is often considered to be one of the most important success factors for enterprise system implementations and has even be referred to as a critical success factor. In this paper a definition of OCM will be proposed and outcomes of an investigation into the effectiveness of integrating OCM when implementing enterprise resource planning projects will be discussed. For the purposes of this investigation large scale enterprise resource planning systems were chosen as the software of choice to study. These systems by virtue of their complexity and implementation costs often cause long reaching impacts on the organization. Often to the point where organizations can wait for long periods of time to obtain any real benefit realisation. In this study 208 European organisations responded to a survey. Findings in brief indicated that experts who applied CM in their projects evaluated their projects as more successful than projects without $\mathrm{CM}$.
\end{abstract}

Keywords: ERP, Organizational change management (OCM), CSFs, Organizational readiness for change

\section{INTRODUCTION}

The benefits that enterprise systems provide organisations have been well documented by many researchers identifying a range of factors contributing to the growth in the uptake of ERP systems; the need to streamline and improve business processes and better manage information systems expenditure. Clearly such systems are essential for modern businesses [1-6]. However, these systems are complex and for many companies, implementations are associated with project overruns and lack of benefit realisation. 


\subsection{Enterprise System and Change}

The very nature of enterprise systems causes enterprise wide business process changes, job redesign and often an associated reduction in head count [7]. It is clearly evident that these are direct employee impacts. As many as $75 \%$ of organisational change efforts involving technology fail as a result of people's negative reactions to changes in their work practices, organisational business processes and in the use of the technology leading people to resist the change $[8,9]$. Consequently, it is the way in which staff are enabled to positively adapt to this change in their work practices, that has been identified as one of the leading critical success factors in successful implementations; the associated interventions are referred to as "change management" [10-13].

One such study indicated that respondents were very aware of the importance of effective change management in ERP implementations [13]. A qualitative question in this survey required IT professionals to provide a short description or definition of change management in order to assess their understanding of this concept [13]. From an analysis of the descriptions, an aggregated definition was developed:

Change management is defined as the process of assisting the organisation in the smooth transition from one defined state to another, by managing and coordinating changes to business processes and systems. Change management involves the effective communication with stakeholders regarding the scope and impact of the expected change; formal processes for assessing and monitoring the impact of the change on the stakeholders and their work processes, and identifying and developing effective and appropriate techniques to assist stakeholders to cope and adapt to the new technology.

It is argued that this definition is inclusive in that it clearly identifies some of the main critical factors involved in change management and takes a holistic approach. The definition applies to change management in a specific condition; that of technology change.

In this paper the impact of enterprise systems, specifically the implementation of SAP (ERP system) will be assessed on organizational change in European countries. The outcome of this assessment on organizational change will be discussed.

\subsection{Survey}

The main objective of this study was to analyze the role of change management (CM) within SAP projects and to learn the adopters' experiences with Change Management.

The ability to successfully implement an SAP system calls for involving the affected business departments and individuals in the change process and convincing them of the project's overall benefits. Overcoming resistance and obtaining user buyin for new systems and methods of working are just some of the key elements of an effective organizational CM program. This study was designed to answer the following questions:

1. What role does change management $(\mathrm{CM})$ play within large scale enterprise system implementations such as SAP? 
2. What are the key drivers for applying CM?

3. Which $\mathrm{CM}$ measures have been applied?

4. What is the impact of $\mathrm{CM}$ on the project's success?

\subsubsection{Survey Design}

An online anonymous study was used. The questionnaire was primarily constructed of closed questions with preformulated answer categories. Some open, explorative questions were included in the questionnaire to provide additional support to closed answers. The questionnaire was structured into six parts: Demographic information about the participating organization, General information about the project, Training, Organizational $\mathrm{CM}$, project success and future prospects.

\subsubsection{Description of the Sample}

In total 208 organizations responded to the survey, mainly from Germany, Switzerland, Austria, the Netherlands, France, Spain Sweden and the United Kingdom. Of these 155 organizations indicated that they had applied CM within their projects; 53 had not. The participating organizations represented a broad range of industries and sizes in terms of the number of employees and annual revenue.

\section{RESULTS}

In total approximately $50 \%$ of the participating organizations belonged to the manufacturing industry sector. One third of the participants were service industries and $18 \%$ were from financials and public sector. Nearly one third of the polled organizations employ up to 1000 people. Another third employ between 1000 and 5000 people. And $11 \%$ have more than 50,000 . It is probably not surprising to note that the higher the application of CM in SAP projects linked to the higher the number of employees. Almost $90 \%$ of organizations with more than 5000 employees applied $\mathrm{CM}$ in their SAP projects, only about half of the organizations with fewer than 1000 employees did. Further, companies with higher revenues tended to integrate $\mathrm{CM}$ more than those with lower annual incomes.

\subsection{Description of Projects}

\section{Project Phase and Duration}

Over half of the projects $(46 \%)$ had already been completed by the time of the Survey enabling organizations to contribute experiences from the whole implementation cycle. More than one-third of the SAP projects lasted one year, and one-third lasted two to three years. Long-term projects with a duration of four years 
or longer made up $23 \%$ of the sample. The decision to apply CM in a SAP project did not depend on the project's duration.

\section{Project budget}

Participants were asked to estimate the total budget for the SAP projects (including licenses and consulting and support services). The majority of the projects (54\%) budgeted less than $€ 2.5 \mathrm{~m}$. A third of the projects had a budget between $€ 2.5 \mathrm{~m}$ and $€ 20 \mathrm{~m}$ and $20 \%$ had a budget of more than $€ 20 \mathrm{~m}$. By comparing projects with and without CM, a general trend was observed: The higher the total project budget, the higher the percentage of projects with $\mathrm{CM}$.

Project complexity

The sample mainly consisted of small projects. Nevertheless, comparing projects with and without $\mathrm{CM}$ reveals a connection between the use of $\mathrm{CM}$ and project size: With increasing project size, $\mathrm{CM}$ was applied more frequently, and nearly all large SAP projects were supported by $\mathrm{CM}$. In more than $50 \%$ of the projects, the implementation of SAP software caused large organizational changes. This clearly underscores the fact that SAP projects are organizational projects. The data analysis revealed a light trend: The more international the project scope, the more prevalent was $\mathrm{CM}$.

\subsection{Levels of Employee Resistance}

Participating experts were asked to evaluate the resistance of different stakeholder groups within their organization toward the SAP project. As Figure 1 demonstrates, the level of resistance correlates with the hierarchical level of the stakeholder groups: the lower the level the higher the resistance.

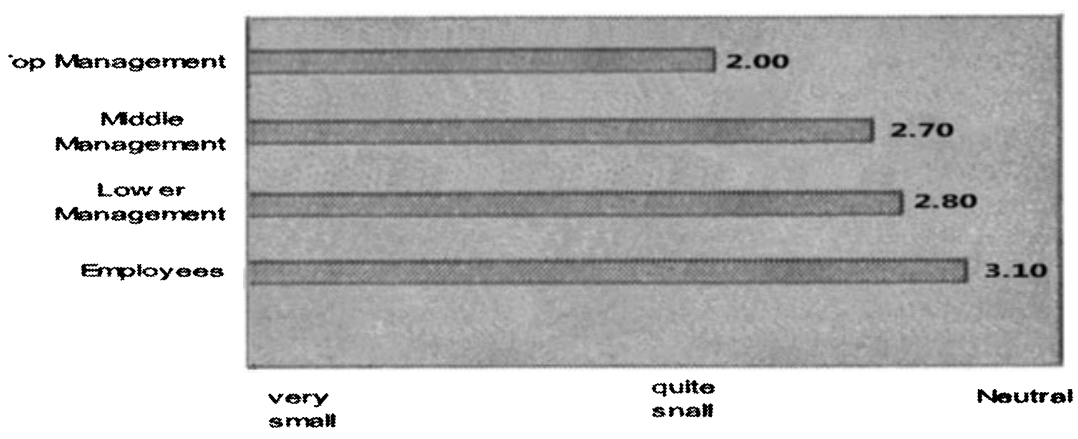

Figure 1. Expected Resistance by Stakeholder Groups

Further analysis indicated there was less resistance for smaller projects compared with midsize or large projects. Findings did indicate that the greater internationality of a SAP project, the higher the probability of resistance. 
The Human Side of ERP Implementations: Can Change Management Really Make a

\subsection{Obstacles in SAP Projects}

Difference?

The experts were asked to describe the main obstacles encountered in their SAP projects. The answers were grouped into five categories: organizational changes*, technical changes, cultural changes*, lack of involvement* and project management. Only three groups $\left(^{*}\right)$ are discussed below and include selected statements from participants:

Table 1. Obstacles in SAP Projects

\begin{tabular}{|c|c|c|}
\hline Groups & Main obstacle & Qualitative answer \\
\hline \multirow[t]{6}{*}{$\begin{array}{l}\text { Organizational } \\
\text { changes }\end{array}$} & $\begin{array}{l}\text { Lack of definition of process } \\
\text { scope and new processes }\end{array}$ & $\begin{array}{l}\text { The main obstacle was an agreement on } \\
\text { standardized definitions and processes }\end{array}$ \\
\hline & $\begin{array}{l}\text { Process standardization and } \\
\text { harmonization }\end{array}$ & $\begin{array}{l}\text { From regional processes to global } \\
\text { processes and the corresponding } \\
\text { responsibilities }\end{array}$ \\
\hline & $\begin{array}{l}\text { Consideration of local } \\
\text { requirements }\end{array}$ & Country specific legal requirements \\
\hline & $\begin{array}{l}\text { Lack of transparency on } \\
\text { organizational changes }\end{array}$ & $\begin{array}{l}\text { The impact was not made clear for the } \\
\text { organization and this has been a major } \\
\text { obstacle }\end{array}$ \\
\hline & Losing Power & $\begin{array}{l}\text { International support for the project was } \\
\text { sliding away because of shifting power } \\
\text { balance between countries and BU } \\
\text { organization }\end{array}$ \\
\hline & New Roles & $\begin{array}{l}\text { Change in roles and responsibilities } \\
\text { Change in work content }\end{array}$ \\
\hline \multirow[t]{3}{*}{$\begin{array}{l}\text { Cultural } \\
\text { Changes }\end{array}$} & $\begin{array}{l}\text { Change of mindset } \\
\text { new way of working }\end{array}$ & $\begin{array}{l}\text { Old habits } \\
\text { Get used to SAP way of working } \\
\text { Stick to the old; new processes are } \\
\text { always worse } \\
\text { Cultural differences between countries }\end{array}$ \\
\hline & Language barriers & Lack of English capabilities \\
\hline & Transparency & $\begin{array}{l}\text { Affected people in some areas (who) } \\
\text { didn't want to put their cards on the table } \\
\text { to emphasize their importance or to save } \\
\text { their workplace. }\end{array}$ \\
\hline \multirow[t]{3}{*}{$\begin{array}{l}\text { Lack of } \\
\text { involvement }\end{array}$} & $\begin{array}{l}\text { Missing top management } \\
\text { support }\end{array}$ & $\begin{array}{l}\text { Increased centralization worries top } \\
\text { management in business units }\end{array}$ \\
\hline & $\begin{array}{l}\text { Missing involvement of } \\
\text { business departments (such } \\
\text { as experts }\end{array}$ & $\begin{array}{l}\text { Due to overlapping activities and missing } \\
\text { understanding }\end{array}$ \\
\hline & $\begin{array}{l}\text { Missing commitment of } \\
\text { middle and lower } \\
\text { management }\end{array}$ & $\begin{array}{l}\text { Top management was involved but } \\
\text { middle management was expecting that } \\
\text { 'the team' would solve all issues." } \\
\text { Middle management fear the SAP } \\
\text { implementation (will) not let them have } \\
\text { their own results anymore }\end{array}$ \\
\hline
\end{tabular}




\subsection{Change Management}

The study shows a clear connection between experience with $\mathrm{CM}$ and later use of it: Nearly all organizations with high and very high CM experience used $\mathrm{CM}$ to support their SAP projects. In contrast, only about $40 \%$ of the organizations with very low CM experience decided to incorporate $\mathrm{CM}$ in their SAP project.

The following summarises the participants' answers to questions focusing on the use of CM in SAP implementation projects. Organizations that decided against applying $\mathrm{CM}$ were asked for their reasons. Summarising these answers, three reasons are identified:

1. First they just did not see the necessity of CM.

Comments included: "Change management was not implemented explicitly and rather (was) applied on demand". It was "not formally done. Change was managed as project issues occurred". They believed also that "the technical and organizational implementation is absolutely sufficient for realising a SAP project." Furthermore, CM was considered "a management task."

2. Secondly they lacked experience with $\mathrm{CM}$ : "The term 'change management' was not known in the project."

3. And finally, many organizations did not provide the project with the necessary financial and/or personnel resources. Linking to the lack of change management in smaller projects.

Experts were asked who made the decision to establish CM in the SAP project. In most projects it was either the project manager $(59 \%)$ or the steering committee (44\%). Less frequently the decision was made by the organizational top management. A further $22 \%$ viewed external partners as the responsible decision makers!

Change Management objectives

Study participants were asked to choose their three most important objectives from a predetermined list. As shown

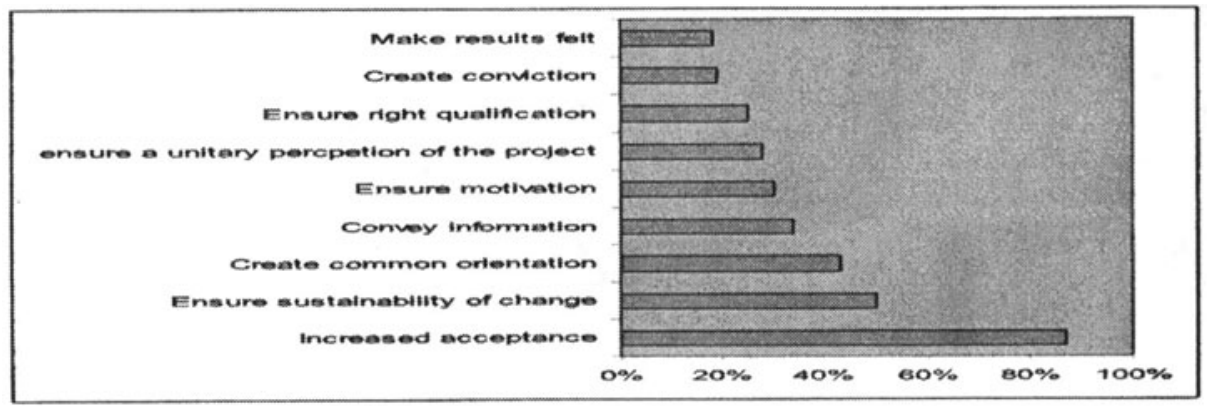

Figure 2. Change Management Objectives

\section{Change Management Budget}

A key issue for any CM project is the financial resources provided for the planned $\mathrm{CM}$ activities. Participants were asked to estimate the percentage of their project's total budget spent for $\mathrm{CM}$ activities not including end user and project team training. 
Almost half of the projects allocated less than $5 \%$ of the overall project budget to $\mathrm{CM}$ activities.

\section{Change Management Measures}

Change management encompasses a large number of different measures. For the survey, the measures were clustered into five groups: Change management analysis, information and communication, training, participation, and further supporting measures. In general a CM analysis (for instance communication and training) is usually applied at the beginning of a project.

As shown in Fig. 3 almost all organizations systematically identified the employees affected by the project $(92 \%)$ and were convinced that this is a value-adding activity. To a lesser extent, the participating organizations were convinced of the analysis of information and communication requirements $(75 \%)$ and the analysis of consequences of the process changes $(70 \%)$ for the affected employees.

Only $50 \%$ of the participating organizations analysed the attitudes and expectations of the affected employees. These organizations risk miscommunication as a result of not focusing on the real needs of the affected employees.

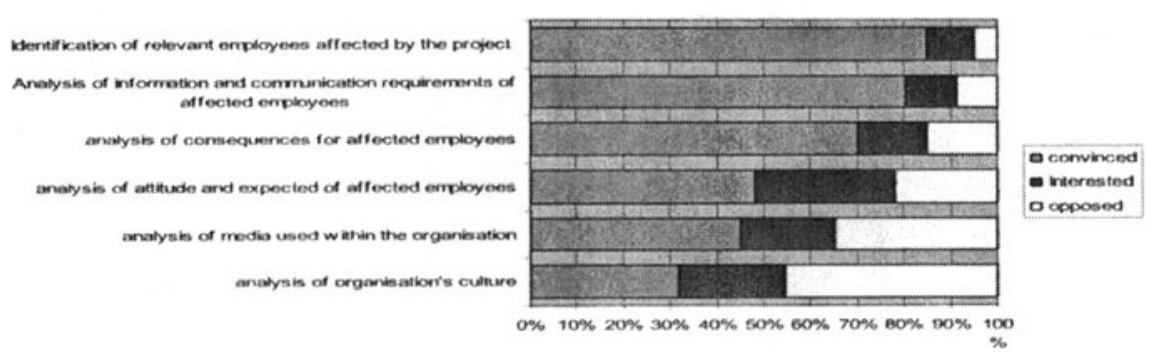

Figure 3. Change Management Analysis

\subsection{Information and Communication}

SAP projects typically affect numerous target groups of an organization, including SAP end users, middle and top level management, IT experts and internal consultants. This section examined how communication occurs and what it consists of in SAP projects.

Communication was identified under three categories: personal, electronic and paper-based. Personal information was identified as being; informational meetings, workshops and personal exchanges. These types of communication measures are considered the most effective ones for supporting change processes.

Electronic communications measures that are inexpensive and easy to handle, such as e-mails, electronic newsletters and intranet pages are favoured over more complex measures such as videos and DVDs. Paper-based communication was used less frequently than electronic. 


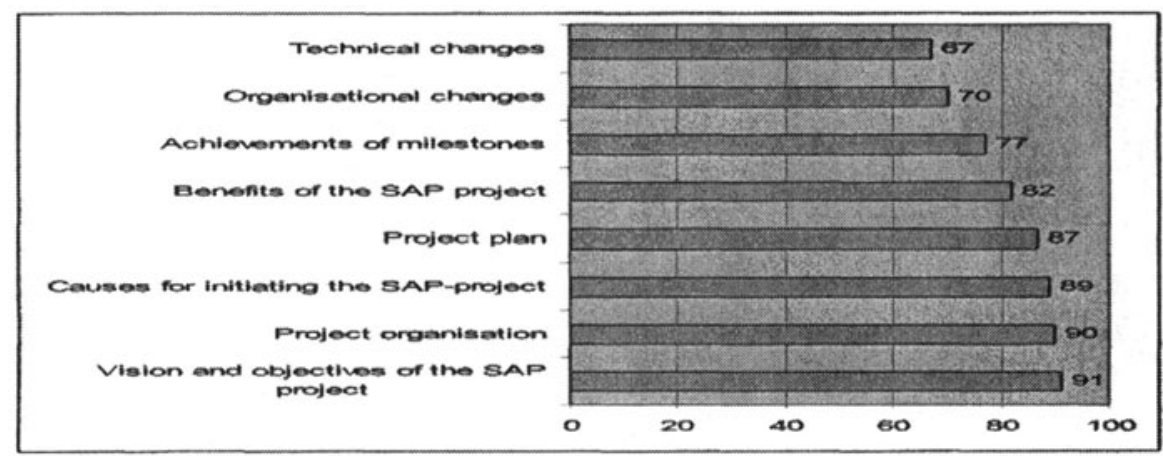

Figure 4. CM Communication Content

In addition to the types of communication, participants were asked about the content of their communication activities. More than $90 \%$ stated that generic topics such as vision, objectives and reasons for implementing SAP software, as well as the project plan and the project organization were especially communicated. A positive finding is that more than $70 \%$ of the participants said they informed their employees about organization and technical changes.

\subsection{Training}

The majority of the participating experts considered training activities as part of CM. The key results can be summarized as follows: Eighty percent of the experts had applied traditional training measures such as classroom training for end users and "train the trainer" concepts. In contrast e-learning tools were used in only every fifth project, but there is a clear trend to apply this newer training tool method more often in future projects. Many organizations were convinced of the "train the trainer" concept. Therefore, external resources were mostly used to train project team members and prospective trainers. Consequently, end users were mainly enabled internally.

\subsection{Evaluating Benefits of CM}

Participant's experiences with CM controlling activities were identified as being around $40 \%$ of the participants developed a specific business case (cost benefit analysis for $\mathrm{CM}$ ). In addition an equal percentage of experts saw a high possibility of evaluating the benefits of CM. Obviously a prerequisite of such measurement is properly defining KPIs. Defining the right KPIs to measure the benefits of CM is an important precondition but it is also necessary to define the right tools or methods to obtain this information. One of the favoured KPIs is employees' acceptance of new processes and systems after go-live. The participating experts mentioned several tools or methods to evaluate this: 
The Human Side of ERP Implementations: Can Change Management Really Make a

Difference?

- Surveys and interviews covering different topics, such as satisfaction and acceptance Indicated most often) - More than $60 \%$ of the experts were convinced of the value of interviewing end users; surveys were conducted in only half of the projects.

- Workshops with the business and/or key users

- Pre- and post-go-live evaluations - "Find out the expectations of people before the project and ask them again after the project is six months live"

- Comparison of projects with and without CM

- Benchmarking against own projects and/or other companies' projects

\subsection{Impact of Change Management on Project Success}

Participants were asked to evaluate the influence of $\mathrm{CM}$ on the overall success of SAP projects; $90 \%$ who applied CM considered the influence on project success to be very high. Interestingly two thirds of the experts who did not apply $\mathrm{CM}$ in their projects also rated the influence of $\mathrm{CM}$ on a project's success. To evaluate the exact impact of CM on the overall success of SAP projects, projects with and without $\mathrm{CM}$ were compared with 11 listed success factors; such as: The end users are satisfied with the new SAP solution. In all instances projects with $\mathrm{CM}$ performed better on all counts than projects without $\mathrm{CM}$.

Many participants offered comments pointing out the importance of $\mathrm{CM}$ in their SAP projects. Insights into their perceptions of $\mathrm{CM}$ are highlighted by the following comments:

- " $\mathrm{CM}$ is one of the critical success factors of a big implementation project, especially when organizational changes are involved."

- "CM is really an added value in an SAP implementation."

- "It is conditional for the success of an SAP project."

- "To make a major change in work processes combined with new tools without CM is simply not an option. Without CM an SAP implementation is a recipe for disaster, as the work would grind to halt."

- "There can be no lasting change (sustainability) without CM."

\section{Summary}

The impact of CM activities on SAP project successes identified that nearly all experts who applied $\mathrm{CM}$ in their projects rated the impact of $\mathrm{CM}$ on the overall project as very high or quite high. Even the majority of participants who did not apply $\mathrm{CM}$ in their actual projects considered $\mathrm{CM}$ to have a noticeable impact on a project's success. Further across all project success criteria, projects with $\mathrm{CM}$ were evaluated as more successful than projects without $\mathrm{CM}$.

\section{Limitations}

Interpretations of the described results must take into account that the results are based on personal ratings and subjective expert judgments related to the implementation of a large enterprise system. CM should be further evaluated from a different - and broader - perspective, and surveys of affected business departments and end users are recommended. Furthermore, longitudinal case studies could be 
used to identify deeper insights in to the effects of different measures and would allow concrete practical recommendations to be deduced.

\section{DISCUSSION}

Enterprise Systems offer a wide variety of benefits to organizations who implement them. However, these systems are fraught with complexity to the point where they often overwhelm a successful implementation leading to project overruns and continued lack of benefit realization. It is hypothesized in this paper that change management plays an important role in the success of large scale enterprise system implementations. In fact organisational change management is often referred to as one of the most important success factors for any enterprise system implementation. To analyse this fact a survey was prepared and sent out to 208 European organizations implementing SAP. The Survey aimed to analyse the role of change management within SAP projects and to learn from the adopters experiences who had implemented CM.

The sample consisted mainly of small projects. However, the comparison of projects with and without $\mathrm{CM}$ reveals a connection between the use of $\mathrm{CM}$ and project size: With increasing project size, $\mathrm{CM}$ was applied more frequently with nearly all large SAP projects being supported by CM. Further in more than $50 \%$ of the projects, the implementation of SAP software caused large organizational changes. The data analysis revealed a slight trend: the more international the scope of the projects, the more prevalent was CM. This could be a reflection on the larger scale of global implementations and the importance of getting 'it' right the first time.

\section{CONCLUSIONS}

The survey findings conclude that $\mathrm{CM}$ is an 'effective' strategy to ensure a successful implementation of a large scale enterprise system. Results indicate that CM supports the transition process that is inherent in any SAP project and therefore contributes to the project's overall success. This was demonstrated on the basis of various success criteria - for instance, short-term project success factors (time, scope and budget) - as well as end-user acceptance and behaviour and long-lasting criteria such as the organisations' ability to accept and learn the new system: Organisational efficacy.

However, CM should be further evaluated from a different - and broader perspective, and surveys of affected business departments and end users are recommended. Firstly that $\mathrm{CM}$ must be considered to be integral to any SAP implementation project and, secondly, that it is identified as a critical success factor covering the human side of SAP software implementations. 


\section{REFERENCES}

1. T. Davenport, Enterprise Systems Revisited: The Director's Cut. Accenture (2003).

2. M. Hammer, How Process Enterprises Really Work, Harvard Business Review. Number11-12, pp.108-118, (1999).

3. Looking for Payback, MIS, eds T. Iggulden (1999), pp.75-80.

4. T. Somer and K. Nelson, The impact of Critical Success Factors across the Stages of Enterprise Resource Planning Systems Implementations, in Proc. of the $34^{\text {th }}$ Hawaii International Conference on System Sciences (2001).

5. M.L. Markus, S. Axline, D. Petrie, and C. Tanis, Learning from Adopters' Experiences with ERP - Successes and Problems, Journal of Information Technology. Volume 15, Number 4, pp.245-265, (2000).

6. P. Hawking, A. Stein, and S. Foster, ERP Post Implementation: A New Journey, in Proc. of the 14th Australasian Conference on Information Systems (ACIS) (Perth, 2003).

7. T. Davenport, J. Harris, and S. Cantrell, The Return of Enterprise Solutions, Accenture (2002).

8. M.L. Markus, Technochange management: Using IT to drive organizational change, Journal of Information Technology. Volume 19, pp.4-20, (2004).

9. M.L. Markus and R.I. Benjamin, The magic bullet theory in IT enabled transformation, Sloan Management Review. Volume 38, Number 2, pp.55-68, (1997).

10. T.M. Somers and K. Nelson, The impact of Critical Success Factors across the Stages of Enterprise Resource Planning Systems Implementations, in Proc. of the $34^{\text {th }}$ Hawaii International Conference on System Sciences (2001).

11. F.F.H. Nah and L.J. Kuang, Critical factors for successful implementation of enterprise systems, Business Processes Management Journal. Volume 7, Number 3, pp.285-296, (2001).

12. S. Shang and P.B. Seddon, A comprehensive framework for classifying the benefits of ERP systems, in Proc. of the sixth Americas Conference on Information Systems (2000).

13. S. Yang and P.B. Seddon, Benefits and Key Project Success Factors from Enterprise Systems Implementations: Lessons from Sapphire 2003. ACIS 2004 (2004), pp.1-10.

14. S. Foster, P. Hawking, and A. Stein, Change Management: The Forgotten Critical Success Factor in Enterprise Wide System Implementations, in Proc. of the 15th Australasian Conference on Information Systems (ACIS) (Hobart, 2004). 